DOI 10.17150/978-5-7253-3001-4.36

A.А. РАСПОПИНА

УДК 656.62(571.53)

ББК 39.42(253.5)

\title{
АНГАРСКАЯ ТРАНСПОРТНАЯ МАГИСТРАЛЬ ЧЕРЕЗ ПРИЗМУ ГОСУДАРСТВЕННОЙ ПОЛИТИКИ
}

В статье рассматриваются вопросы, связанные с попытками организации регулярного судоходства по р. Ангаре, действиями частных предпринимателей и государства по улучшению судоходных условий на всем протяжении реки. Исследуется процесс формирования государственной политики по созданию транспортной инфраструктуры Сибири.

Ключевые слова: Ангара, судоходство, пароходство, А.М. Сибиряков, ангарские пороги, туеры.

\section{A.A. RASPOPINA}

\section{ANGARA TRANSPORT MAIN THROUGH THE PRISM OF THE STATE POLITICS}

In the article are examined the questions, connected with attempts at the organization of regular navigation on r. Angar, by the actions of particular owners and state for an improvement in the navigable conditions for entire elongation of river. Is investigated the process of molding of state policy on the creation of the transport infrastructure of Siberia.

Keywords: Angara, navigation, steam navigation, A.M. Siberians, Angara thresholds, chain-tugs. 
Фернан Бродель, рассуждая о дорогах Средиземноморья, пролегающих по суше, морю, рекам и озерам, писал, что это: «..огромная сеть постоянных и случайных произведений, система вечного жизнеобеспечения, своего рода кровеносная система...» [3, с. 386].

Такой же кровеносной системой для обширных сибирских просторов являлись ее реки - основные транспортные артерии. Они служили путями сообщения не только в период проникновения русских землепроходцев в глубь сибирской территории, но и в дальнейшем - в процессе хозяйственного освоения Сибири, когда речная гладь не редко являлась единственной связующей ниточкой с отдаленными населенными пунктами. Так, пока река не скована льдом и длится навигационный период, грузы доставлялись, и сообщение шло по воде, а с началом зимних холодов, как только ледовый покров на реке достигал необходимой крепости, санная дорога проходила уже по замерзшей реке.

«Дороги и города, представляют собой один и тот же инструмент овладения пространством», - пишет Бродель [3, с. 387]. «Овладение пространством» Сибири давалось очень не просто и не быстро в силу обширности территории и малочисленности населения. Сухопутная дорожная сеть была редкой и в XVIII, и даже XIX вв. Немногочисленные дороги в ненастье и вовсе становились непроезжими. «Еще в начале XVIII столетия путь из Москвы до Иркутска лежал по сибирским рекам Иртышу, Оби и, непременно через Енисейск, Илимск, Братск, Балаганск. Этим направлением пользовались зимой на санях по льду рек и через волоки и летом по воде на парусниках и лодках» [14, с. 4]. В первой половине XVIII в. на больших сибирских пространствах отсутствовало достаточное количество населенных пунктов с русскими жителями, которое позволило бы соединить их дорожной сетью, такая ситуация была характерна и для территории между Красноярском и Иркутском до появления Московского тракта. Однако необходимость организации постоянной бесперебойной доставки почт, правительственных распоряжений, государственных и частных грузов требовала изменения ситуации. В связи с чем, руководствуясь не только административными, но и торговыми соображениями правительство приступило к строительству Московского тракта, которое началось с заселения южных районов Восточной Сибири. Переселенцев размещали в первую очередь вдоль будущего тракта.

C середины XVIII в. движение по Московскому тракту стало круглогодичным, но ангарский водный путь еще не утратил своего значения. Купечество предпочитало доставлять груз водой, получая от этого большие выгоды, чем от сухопутных перевозок. В дальнейшем, сухопутная дорога составила серьезную конкуренцию водному пути по Ангаре, а извозный промысел стал важной статьей дохода притрактового населения. Большой грузопоток, осенняя и весенняя слякоть, или несколько 
дождливых дней летом быстро превращали дорогу в состояние совершенно непригодное для проезда, но использование водного транспорта на всем протяжении Ангары не всегда было возможно и удобно. Так, «по сведениям Иркутского общего губернского правления, в 40-х гг. XIX в. сплав купеческих грузов по Ангаре производился только тогда, когда цены на сухопутную перевозку из Иркутска в Томскую губернию бывают дороги» [11, с. 29]. В отчете генерал-губернатора Восточной Сибири за 1851 г. отмечается, что на сибирских реках развивается преимущественно сплавное судоходства, а вверх по течению суда поднимаются редко и это происходит не только из-за сложных судоходных условий, но и в силу чрезвычайной дешевизны постройки сплавных судов, которые удобнее разобрать на дрова после прибытия на место, чем поднимать их против течения. Но все же основными препятствиями к установлению регулярного судоходства по ряду сибирских рек и в частности по Ангаре являлась неустроенность водных путей. «Сообщение по Ангаре, сопровождаемое частыми шиверами, подводными камнями и опасными порогами не только затруднительно, но и сопряжено иногда даже с разбитием судов и гибелью капитанов» $[12$, л. 6].

Даже в последней четверти XIX в. ситуация с водными и сухопутными путями сообщения не слишком изменилась в лучшую сторону. Так, осенью 1885 г. почта запаздывала в Восточную Сибирь на целый месяц, обозы с купеческими товарами застревали в пути, «...проезжающие бедствовали невыразимо, а обозы с купеческими товарами употребляли на проезд от одной станции до другой (28-30 верст) до недели времени, местные крестьяне брали до 3 р. с воза, чтобы провезти через свою деревню. Такое состояние единственного пути в Сибирь возмутительно» [5, с. 40].

Ангара хотя и являлась довольно протяженной водной магистралью, но регулярное судоходство, не могло совершаться в силу наличия большого количества порогов в среднем течении реки. Поэтому по Ангаре судоходство существовало лишь на отдельных участках, наиболее безопасных для движения судов. Наиболее оживленной была верхняя часть Ангары от истока до Братского острога (608 верст), здесь могли ходить суда с осадкой в 5-6 четвертей (от 0,89 до 1,07 м). Следующий участок пути от Братского острога до устья р. Илим (275 верст) представлял наибольшие трудности, как для сплавного, так и для взводного судоходства. Здесь находились Похмельный, Пьяный и Падунский пороги, из которых последний преодолеть было практически невозможно. Нижний участок Ангары был также неудобным для судоходства, здесь располагались три больших порога: Стрелковский, Мурский и Аплинский и около 20 шивер, быков, кармагулов и мелких мест. «До 1888 г. в этой части Ангары, кроме сплавных судов и паузков с чаями и шерстью, встречались лишь лодки вместимостью до 700-800 пудов, груженые мануфрактурными товарами, 
и приводимые в движение бичевой тягой людьми из Енисейска вверх по реке до Илима и по самому Илиму» [1, с. 476].

Долгое время правительство не стремилось идти навстречу инициативам купцов, предлагавших свои проекты по улучшению судоходных условий Ангары, организации по ней регулярного судоходства и просивших за свой труд субсидии от казны или монополии на осуществление задуманного предприятия. Вложение средств в организацию бесперебойного транспортного сообщения на тот момент казалось еще преждевременным, и возможно считалось экономически нерентабельным. Сибирь хоть и являлась частью России, но внимание власти к ее нуждам было не столь выражено, в силу удаленности, малонаселенности и недостаточного хозяйственного освоения этого края. До середины 80-х гг. XIX в. такие проекты раз за разом отклонялись правительством. В то же время, возраставшие объемы кяхтинской торговли и несомненные преимущества в скорости и дешевизне водной доставки грузов, заставляли сибирских предпринимателей все чаще задумываться о возможности приведения в судоходное состояние р. Ангары. На собственные средства предпринимались отчаянные экспедиции через ангарские пороги. Отчеты экспедиций заслушивались в Восточно-Сибирских отделениях императорского русского технического, а также географического обществах, отчет Романова, спустившегося через пороги, был опубликован в Морском сборнике, но дальше дело не двигалось с мертвой точки. Тем не менее, в результате этих многочисленных исследований, хотя некоторые из них в большей мере можно было назвать «любознательными путешествиями» по Ангаре, в середине 70-х гг. XIX в. была образована «смешанная комиссия из членов Сибирского отдела географического общества и Восточно-Сибирского отделения технического общества, для начертания плана на научных началах основанной экспедиции на Ангару. Комиссия признала необходимость двух экспедиций - одной зимней, а другой - летней» [13, л. 30]. Предполагалось провести пробные взрывы порогов, была составлена смета экспедиций (планировалось затратить 6000 р.) и даже был определен состав будущей партии. Тем не менее, провести запланированные работы не получилось. Все собранные материалы пришлось передать партиям, командированным МПС для исследования сибирских рек. Можно сказать, впервые начинает явственно просматриваться интерес государства.

Именно в это время МПС командировало несколько описных партий в Западную Сибирь - для исследования водораздела рек Оби и Енисея и в Восточную Сибирь - для исследования р. Ангары и ее порогов. Так, в 1775 г. на Ангару была отправлена партия капитан-лейтенанта Чалеева и инженера коллежского секретаря барона Аминова. Основной задачей экспедиции являлось определение возможности установления регулярного судоходства по р. Ангаре и определения «затруднительных 
препятствий» на всем ее протяжении. Рапорт, представленный по завершении работ, был обнадеживающим. По мнению исследователей, требовалось провести дноуглубительные работы и расширить фрарватер Ангары в некоторых местах. «Для приведения реки в такое состояние придется вынуть 25000 пуд. куб. саж. камня и песку и уничтожить до 30 камней, более вышедших на фрарватеры. В быстрых порогах надо будет вероятно прибегнуть к помощи туэров. Расчистка реки потребует расходов не более как на 1500000 руб.» [13, л. 59 об.]. И хотя это были пока первые пробные рекогносцировочные шаги, предпринятые государством, они стали определяющими в деле выработки программы действий правительства по увеличению протяженности сухопутных и водных коммуникаций российской империи.

В целом же, ситуация с сибирскими водными путями практически не менялась вплоть до начала исследовательских и строительных работ по сооружению Обь-Енисейского канала, когда та же Ангара стала рассматриваться в качестве одного из основных связующих звеньев будущего поистине гигантского водного пути, который должен был соединить восточные и западные пределы России. В Вестнике Европы за 1886 г. была опубликована статья, посвященная строительству канала, в ней доказывалась необходимость создания «длиннейшей в мире линии непрерывного речного сообщения», которая, вне всякого сомнения, будет иметь государственное значение. «Так, например, при новом столкновении с Китаем, - писал автор статьи, - если бы оно могло случиться, нам не нужно будет затрачивать десятки миллионов рублей на трудную сухопутную перевозку к сибирской границе войск и на вооружение на ней некоторых пунктов... Не нужно забывать, что, со времени нашего последнего столкновения с Китаем в 1881 г., по кульджинскому вопросу, китайское правительство обнаруживает сильное стремление к развитию своих военных сил и к устройству военных поселений в полосе, пограничной с Россией... Но едва ли не главнейшую услугу для обширной нашей окраины окажет новый пароходный путь в том отношении, что он будет уравновешивать цены на хлеб по всем ее местностям» [4, с. 889-890].

Планирование и проведение государством грандиозных работ, связанных с соединением рек Оби и Енисея судоходным каналом, способствовали новому всплеску интереса к ангарской проблеме. Вновь активизировались сибирские предприниматели, полагая, что в данной ситуации государство обязательно пойдет им навстречу. Так, в 1882 г. купцы первой гильдии - И.И. Игнатов и А.М. Сибиряков направили прошение на имя генерал-губернатора Восточной Сибири Дмитрия Гавриловича Анучина, о предоставлении им привилегии сроком на 15 лет для организации постоянного пароходного сообщения между Иркутском и Енисейском. Из администрации генерал-губернатора последовал ка- 
тегорический отказ. Предложенное купцами предприятие, на взгляд генерал-губернатора, выглядело монополией, чего нельзя было допустить, особенно после того, как по Обь-Енисейскому каналу начнется регулярное движение судов. Строительный департамент Восточной Сибири, желая повлиять на положительный исход дела, рекомендовал ходатайствовать «не о выдаче привилегии, а об учреждении субсидированного пароходного товарищества, наподобие Кяхтинского на Байкале и Амурского. Они, имея уставы и получая от государства субсидии, не мешают другим предпринимателям строить пароходы и организовывать новые пароходные общества» [8, л. 16]. Отказ не охладил пыл Александра Михайловича, наоборот, он принялся деятельно прорабатывать техническую сторону вопроса. Интересовался конструкциями пароходов, продумывал возможность использования на Ангаре судов иностранной конструкции - таких, которые ходили по рекам Северной Америки, консультировался по поводу технической возможности уменьшения осадки пароходов, определения наилучших для ангарских условий ходовых качеств судов.

Настойчиво продвигаясь к своей цели, Сибиряков и Игнатов в 18821883 гг. на свои средство провели очередные исследования Ангары, спустившись по ней на паровом судне, установили, что организация регулярного судоходства через грозные ангарские пороги возможна. Сведения об этой поездке моментально оказались на страницах печати, но реакция общественного мнения оказалась, на первый взгляд, довольно неожиданной. Вместо громких оваций, предприниматели встретили прохладный прием. «Томские губернские ведомости» так отозвались на спуск через пороги: «... мы впервые узнали о причине молчания Игнатова и Сибирякова, которые вероятно находили неудобным оглашать такой факт, как попытку добиться привилегии на пароходство по сибирским рекам, с целью убить других пароходовладельцев, чего мы сибиряки даже не ожидали, от нашего просвещенного земляка - почтенного А. Сибирякова. Путь этот почти не тронутый, с открытием его немало грузов пойдет из Минусинска в Иркутск, так как на убытки рассчитывать нечего, если в одно время с пароходами Компании пойдут и пароходы других лиц, которым всем будет дело; а о пользе этой свободы для края и говорить нечего, потому, что привилегия - родная сестра эксплуатации» [6, л. 139]. «Восточное обозрение» также отозвалось достаточно скептически, движение пароходов, по его мнению, должно быть возможно в обе стороны, а не только вниз по реке. Для этого необходимо выполнить серьезные гидротехнические работы, единичные же случаи спуска через пороги не могут служить доказательством судоходности Ангары, тем более, что она всегда считалась сплавной рекой. Действительно, открытие транзитного сибирского водного пути обещало стать прибыльным предприятием и недостатка в желающих открыть свой па- 
роходный маршрут явно не наблюдалось. Но прежде требовалась всего лишь малость - расчистить ангарский фрарватер, в таком же рискованном и затратном деле охотников было немного. Естественно, затрачивая солидный личный капитал, А.М. Сибиряков возможно рассчитывал в какой-то мере и на государственную поддержку, тем более, что впервые за долгое время государство четко обозначило свои интересы в отношении водных путей. Естественно, что на взгляд предпринимателя, после приведения им реки в судоходное состояние он мог рассчитывать на получение прибыли от привилегии на организацию пароходства.

В ноябре 1883 г. Сибиряков вновь обращается к генерал-губернатору с прошением о выдаче привилегии, но на этот раз - только через ангарские пороги и сроком на 10 лет. Александр Михайлович обязался «...в течение трех лет пустить в плавание в указанной части Ангары не менее двух пароходов с соответственным количеством барж и, открыть правильное сообщение для перевозки тяжестей от города Иркутска до города Красноярска и обратно» [8, л. 79]. Через пороги предполагалось проложить цепь для туэрного пароходства, если же и это не помогало преодолеть каменистые гряды, в таком случае, вдоль берега должна была быть устроена грунтовая дорога. В случае несоблюдения условий привилегия прекращалась.

Прошло несколько месяцев, но никакого ответа не последовало. Складывалось представление, что канцелярия генерал-губернатора намеренно затягивала решение столь важного вопроса, напоминая тем самым знаменитый Падунский порог. Сибиряков пишет новое прошение, в котором детально оговаривает все условия. Он берет на себя обязательство «... не позднее как через пять лет, со дня выдачи привилегии ввести еженедельную перевозку грузов и арестантов от Иркутска до Красноярска или Енисейска и обратно» [8, л. 83]. Ежегодно должны были проводиться работы по поддержанию Ангары в судоходном состоянии, на которые предполагалось затрачивать по 10000 р., перевозка казенных и частных грузов (хотя и без страховки) по строго определенной таксе. Сибиряков предполагал пустить два парохода мощностью не менее 120 номинальных сил каждый с двумя баржами, которые должны были совершать по два рейса в месяц, один от Иркутска до Красноярка, другой - обратно. В течение навигации можно было бы перевозить до 500000 пуд. различных грузов. В прошении Сибиряков оговаривал, что пропуск через пороги буксирных и грузовых пароходов других предпринимателей «может производиться только по взаимному с нами соглашению. Казенные же пароходы могут плавать без всякого нам вознаграждения» $[8$, л. 82].

Несомненно, Д.Г. Анучин осознавал все выгоды организации регулярного пароходного сообщения по Ангаре, принимая при этом во внимание, что это потребует значительных финансовых затрат и относясь 
к делу, как он сам отмечал, «с достаточным сочувствием», все же не мог согласиться требованиями А.М. Сибирякова. Возможно, здесь примешивалось что-то еще, может даже личная неприязнь. Иначе сложно объяснить наличие конфиденциального письма Дмитрия Гавриловича Анучина Константину Николаевичу Посьету, в котором он писал: «он [Сибиряков] без сомнения обладает достаточными средствами для таких предприятий, как устройство пароходства по Ангаре, тем не менее, я нахожу, что вследствие своих индивидуальных особенностей он лицо совсем не подходящее для этого дела и вообще, не способное ни на какие серьезные предприятия» [8, л. 100]. Генерал-губернатор представил предпринимателя в очень невыгодном свете, «...почти ежедневно меняет свои намерения и распоряжения. Едва ли было бы удобно правительству входить с ним в какие бы то ни было обязательства» [8, л. 101].

Сибирская пресса живо интересовалась ситуацией вокруг сибиряковского проекта, и статьи на эту тему, чаще всего осуждающие монопольное предприятие, время от времени появлялись на страницах газет. Очередная статья вышла в 1884 г. в «Енисейских губернских ведомостях». Текст статьи полностью соответствовал мнению Д.Г. Анучина. Автор писал о том, что условия Сибирякова были настолько невыгодны, что привилегия, а вернее - монополия могла лишь затормозить «на 10 лет всякое движение по вновь открываемому пути», признавалась несомненно высокой такса за провоз грузов через ангарские пороги. Общественность опасалась того, что при отсутствие четкой регламентированной цены на провоз грузов на тех участках реки, которые свободны от каменистых гряд, Сибиряков сможет установить сначала самые минимальные цены, что полностью устранит конкуренцию, а затем поднимет плату для транспортировки грузов по всей Ангаре. Поэтому, делалось заключение, такая монополия могла лишь негативно сказаться на интересах торговли и промышленности как Сибири, так и Европейской России.

До тех пор, пока необходимость улучшения судоходных условий на сибирских реках связывалась преимущественно с коммерческими интересами сибирского предпринимательства, особенно принимая во внимание малонаселенность обширного края, правительство не стремилось, да и не могло по объективным причинам финансировать подобные предприятия. В 80-е гг. XIX в. наблюдается некоторое изменение правительственного курса. В правление Александра III вопросы внутренней политики становятся особо приоритетными, активно ведется городское строительство, улучшается инфраструктура. Именно в это время происходит переориентация внешней политики России на Восточно-Азиатское направление. Теперь актуальным вопросом является уже не соединение сибирских рек в единый водный путь, а строительство 
Транссибирской железнодорожной магистрали, необходимость которой, несомненно, связана с решением геополитических задач. И в этой связи, регулярное пароходство по Ангаре, изобилующей порогами и шиверами, становится жизненно необходимым, оно может ускорить железнодорожное строительство, облегчит подвоз необходимых материалов и оборудования. Потому прошение Сибирякова, поданное уже в МПС, о предоставлении ему привилегии на организацию пароходства через пороги, приведение в судоходное состояние Ангары, идущей параллельно будущей проектируемой железнодорожной магистрали, чрезвычайно важной в военно-стратегическом отношении, было благосклонно встречено правительством.

Произвести расчистку русла Ангары на средства казны пока не представлялось возможным. В связи с чем, Министерство путей сообщения приняло решение воспользоваться предложением А.М. Сибирякова об устройстве на свой счет буксирного и пассажирского пароходства в порожистой части р. Ангары. Испрашиваемый же предпринимателем пятилетний срок привилегии был признан довольно незначительной уступкой в деле столь важного государственного значения.

Сибиряков рассчитывал, что самый сложный участок реки с порогами Пьяным и Похмельным, после небольшой расчистки будет вполне доступен для пароходов. Наибольшее затруднение, по его мнению, представлял лишь Падунский порог «водопадного типа». Спустившийся через пороги Д. Романов, (он опубликовал путевой дневник в Морском сборнике) отмечал большое и крутое падение в самом пороге -4-5 саж. на версту, а буквально перед порогом - наличие шиверы (длиной около 150 саж.), с узким и извилистым фрарватером, который был чрезвычайно сложен для движения судов. А.М. Сибиряков рассматривал возможность устроить здесь систему шлюзов или как вариант - обходной канал, в крайнем же случае - провести грунтовую или конно-железную дорогу. Интересно, что Александр Михайлович замахнулся на строительство обходного канала, учитывая его знакомство с местностью рядом с Падунским порогом. Берега Ангары в этом месте представлены высокими скальными обнажениями, это объясняется особенностями геологии ангарской долины. Что представляла собой Ангара, ее пороги и шиверы в последней четверти XIX в. можно увидеть на фротографриях, сделанных описной партией Чалеева и Аминова.

17 августа 1885 г. положение о предоставлении А.М. Сибирякову привилегии на организацию ангарского пароходства было Высочайше утверждено. Он должен был организовать Товарищество на вере или пароходную компанию и в течение двух лет открыть пароходное сообщение, пустив не менее двух 120-сильных пароходов с баржами. Ежегодно, перед началом навигации суда должны были освидетельствоваться специальной комиссией, назначенной местным начальством. 
Осуществить задуманное оказалось не так просто, прокладка цепей через пороги оказалась слишком трудоемка, затягивалось и строительство судов. В этой связи, Комитет министров разрешил вести отсчет срока привилегии с навигации 1887 г., затем отложил до 1888 г. и, наконец, принял решение о начале пароходного движения с 1889 г.

19 апреля 1889 г. в «Иркутских губернских ведомостях» было опубликовано объявление об открытии в предстоящую навигацию пароходных рейсов между Енисейском и устьем Илима. Регулярные рейсы должны были совершаться пароходами: «Святой Иннокентий», «Святой Николай» и «Илим». Сибирякову удалось открыть движение в нижней части Ангары (от устья до Илимска), но основной, самый опасный и порожистый участок, со знаменитыми порогами - Похмельным, Пьяным и Падунским преодолеть оказалось не под силу. Через некоторое время Александр Михайлович отказался от поставленной цели и ликвидировал предприятие.

В 1894 г. казна выкупила принадлежащее Сибирякову туерное пароходство за 194430 р. 38 к.: баржи «Илим» и «Мура», туеры старой конструкции - «Святой Иннокентий» и «Илим», мощностью в 60 и 30 номинальных сил соответственно, а также 15 верст цепей, общим весом до 195 пуд, уложенных в Стрелковском, Мурском, Аплинском и Шаманском порогах» [15, с. 10]. Привести Ангару в судоходное состояние силами только частных предпринимателей оказалось невозможно, слишком велики были не только материальные, но и трудозатраты.

Использовать водный путь по Ангаре всегда представлялось чрезвычайно заманчивым. Широкая (до 800-1000 м), быстрая, достаточно глубокая на отдельных участках, с большим количеством островов, многие из которых были даже заселенными, на первый взгляд она могла быть приспособлена для регулярного судоходства, особенно это касалось верхнего и нижнего течения реки. Средний участок Ангары был наиболее сложным из-за наличия самых опасных порогов, что объяснялось геологическим строением ангарской долины. На этом участке долина Ангары суживалась, берега становились высокими со сплошными скалистыми обнажениями. В порогах реку пересекали гряды кристаллического диабаза - траппа. На всем своем протяжении Ангара то собиралась в одно русло (преимущественно в порогах, где оно сжато скалами), то разбивалась на отдельные рукава, которые расходились на расстояние до нескольких км. Некоторые пороги и шиверы были достаточно протяжены, так, Долгий порог представлял собой 6-ти км. препятствие, ниже начинались «Шаманские препятствия, растянувшиеся на 19 км, в число которых входят «Шаманская шивера», затем «Шаманский бык» и, наконец, «Шаманский порог» [9, с. 16]. Особую опасность представляла огромная скорость водного потока в порогах. Так, Падунский порог, образованный каменистой грядой, занимающей 
до 2/3 ширины реки, был самым опасным. Его «минимальная глубина определяется в 80 см. Наибольшая скорость течения 16 км в час. Общее падение порога - 6,5 м. В Долгом пороге Ангара представляет собой стремнину, сдавленную отвесными скалистыми берегами, высотой от 40 до 65 м и перегороженную рядом каменистых гряд. Ширина реки составляла здесь около 650 м, уменьшаясь в конце порога до 500 м. Скорость течения достигала 15 км в час. Шаманский порог, второй гигант на Ангаре, имел общее падение 13 м» [9, с. 16]. Для того, чтобы сделать возможным регулярное судоходство по Ангаре, требовались серьезные капиталовложения и огромный комплекс гидротехнических работ, осуществить которые можно было только при участии государства, до тех пор Ангара могла использоваться лишь на отдельных относительно безопасных участках.

В конце 80-х - начале 90-х гг. XIX в. вопрос покорения Ангары, не смотря на предыдущие неудачи, всецело захватил правительство. Началось строительство Транссибирской железной дороги и Ангару предполагалось использовать для подвозки по ней необходимых строительных материалов. В 1887-1889 гг. на Ангаре работала описная партия Департамента шоссейных и водяных сообщений под руководством инженера Чернцова. «Партией была рекогносцировочно заснята вся Ангара на всем ее протяжении и составлена крупномасштабная карта с детализацией отдельных участков опасных для судоходства (пороги и шиверы)» [2, с. 6]. В это самое время А.М. Сибиряков, на основании выданной ему привилегии, занимался расчисткой фарватера Ангары и прокладкой цепей в порогах для организации пароходного движения. Изыскания, проведенные партией Чернцова, заставили убедиться в том, что уложиться в незначительные средства, которые планировалось потратить для расчистки реки и проделать это в короткий срок, определенный для проведения работ, с целью приспособить Ангару к взводному и сплавному судоходству невозможно. Не удивительно, что частные предприниматели не смогли справиться со столь сложной задачей. После того, как Сибиряков сошел с дистанции, поняв, что не в силах преодолеть созданные природой преграды, за решение ангарской проблемы взялось государство.

Проведя детальные исследования Ангары, Чернцов отмечал, что судоходство по Ангаре вполне возможно и преграды могут быть устранены, но только лишь до Шаманского порога. От Шаманского порога и до Падуна плавание «сопряжено с риском, который может быть облегчен, но не устранен вовсе; риск этот заключается в случайных засорах цепи в быстринах и тесных местах порога и частых разрывах цепи. В Падуне плавание в самом пороге невозможно» [15, с. 24].

После приобретения казной пароходства Сибирякова начался новый этап дноуглубительных работ на Ангаре. Железнодорожное стро- 
ительство еще не было завершено, требовалась срочная организация работы Байкальской паромной переправы и доставка грузов по Ангаре была жизненно необходима. Правительство готово было затратить солидные средства для организации бесперебойного судоходства по этой реке. Работы начались. Из русла реки было «удалено 759,37 куб. саж. камня, уложены туерные цепи в пяти порогах, построены туеры и произведена обстановка фарватера. В результате этих работ, продолжавшихся в 1894-1899 гг., обошедшихся государству в 1755000 р. была достигнута транзитная глубина в 5/4 аршина по всей Ангаре, за исключением Падунского порога, где слишком большие скорости течения не допускают взводного судоходства без шлюзования» [10, с. 31]. Чернцов отмечал, что углубить судовой ход до 7 четвертей аршина, как предполагалось первоначально, оказалось невозможно из-за того, что мелководные места были не только в порогах, но и на плесах (тянущихся иногда по нескольку верст), расчистить которые на запланированную глубину при ограниченных средствах «совершенно немыслимо».

После завершения всех работ планировалось использовать Ангару для перевозки по ней нескольких млн. пудов груза. Водный путь по Ангаре все более приобретал государственное значение. Управлением по сооружению Сибирской железной дороги, помимо приобретенных у Сибирякова судов, было дополнительно заказано в Англии два сильных и быстроходных парохода, которые смогли бы «буксировать караван из четырех барж, с общим грузом 75000 пуд., при осадке пароходов и барж $31 \frac{1}{2}$ футта, со средней скоростью 10 верст в час» [7, л. 90]. Tуерные пароходы «Первый» и «Второй», заказанные в Англии, обошлись казне в 286657 р., они прибыли к устью Енисея к навигации 1894 г. Хотя фрарватер Ангары был, можно сказать, подготовлен для рейсирования судов, но предприятие это по-прежнему оставалось рискованным. Самым опасным порогом, укротить который вновь не получилось, оставался Падунский порог. Для того чтобы обойти его, было решено построить по левому берегу Ангары железнодорожную колею длиной 2,5 версты с двумя пристанями - выше и ниже порога.

Доставка казенных грузов начала осуществляться следующим образом: на пароходах по Енисею и Ангаре до Падуна, здесь перегрузка на железнодорожные составы (в обход порога), затем перегрузка на баржи, которые буксировались пароходами до Иркутска или Байкала. Все остальные ангарские пороги преодолевались с помощью туерных устройств, но даже туерное пароходство было сопряжено с риском: разрывы и засоры цепей в порогах, аварии пароходов, периоды маловодья, когда пароходы вынуждены были долго стоять в ожидании подъема воды. Немало неприятностей доставлял донный лед, образующийся при замерзании Ангары, перемещающий громадные камни, он нередко выносил на поверхность туерные цепи. 
Когда железная дорога до Иркутска была построена, МПС отказалось от использования ангарского пути. Затраты на организацию пароходства и поддержание судоходного состояния фрарватера Ангара оказались слишком обременительны даже для государства. Грузоперевозки по железной дороге обходились дешевле, быстрее и безопаснее. Тем не менее, казенное пароходство не планировалось просто расфрормировать. Еще в 1898 г. было принято решение о необходимости поиска частного предпринимателя, который согласился бы взять на себя осуществление пароходных рейсов с навигации 1899 г. Были разработаны особые условия бывшим управлением по сооружению Сибирской железной дороги, на которых могла состояться передача «на арендном праве в полное и непосредственное их распоряжение всех построенных казной зданий, пристаней, мастерских с их оборудованием, а также имеющиеся на этой реке пароходы, туеры и т.д. ...Содержание и ремонт обстановки пути, туерных цепей и остальные устройства, имеющие целью улучшение судоходных условий реки вместе с их содержанием и ремонтом предполагалось производить казной, для чего за ее же счет предполагалось установить технический надзор» [15, с. 23]. Продажная цена, кроме цепей, построек и некоторых материалов определялась в 150000 р., но никто из сибирских предпринимателей не отважился взять на себя столь рискованное предприятие. Не было совершенно никаких гарантий, что затянувшееся мелководье, аварии судов вследствие разрыва или засорения туерных цепей в порогах, или еще какие-либо причины не поставят предприятие на грань банкротства.

Казенное ангарское пароходство пришлось рассрормировать. Туер «Первый» был переведен через Объ-Енисейский канал на р. Обь, пароход «Святой Иннокентий» работал вплоть до середины XX в. на Енисее, туер «Второй» был переведен в обход Падунского порога и доставлен на оз. Байкал, где вошел в состав Байкальской паромной переправы. Вместе с ним состав переправы пополнили паровые ангарские катера «Стрела» и «Бард».

\section{Список использованной литературы и источников}

1. Асалханов И. А. Социально-экономическое развитие юго-восточной Сибири во второй половине XIX в. / И. А. Асалханов. - Улан-Удэ : Бурят. кн. изд-во, 1963. - 493 c.

2. Астраханцев В. И. Ангара и ее бассейн / В. И. Астраханцев // Труды Восточно-Сибирского геологического института. - М. : Изд-во СО АН СССР, 1962. - 92 с.

3. Бродель Ф. Средиземное море и средиземноморский мир в эпоху Филиппа II : в 3 ч. Ч. 1: Роль среды / Ф. Бродель ; пер с фр. М. А. Юсима. - М. : Языки славянской культуры, 2002. - 798 с.

4. Вестник Европы - 1886. - Т. 1, № 2. - С. 889-896.

5. Всеподданнейший отчет и.д. генерал-губернатора Восточной Сибири. СПб., 1886. -56 с. 
6. ГАИО - Ф. 31. - Оп. 3. - Д. 293. - Л. 139 (Томские губернские ведомости. $-1883 .-28$ апр.).

7. ГАИО - Ф. 31. - Оп. 3. - Д. 299.

8. ГАИО - Ф. 31. - Оп. 3. - Д. 313.

9. Гранина А. М. Геологическая экскурсия по р. Ангаре / А. М. Гранина, М. М. Одинцов. - Иркутск : [тип. газ.], 1947. - 36 с.

10. Малышев В. М. Исследования рек Восточной Сибири / В. М. Малышев, И. Ф. Молодых. - Иркутск, 1924. - 53 с.

11. Распопина А. А. Транссибирская водная магистраль: разработка проектов / А. А. Распопина // Земля Иркутская. - 2004. - № 3 (26). - С. 28-33.

12. Российский государственный исторический архив (РГИА). - Ф. 169. Оп. 1. - Д. 6.

13. РГИА - Ф. 180. - Оп. 1. - Д. 11.

14. Хобта А. Начало устройства Московского тракта в Иркутской губернии / А. Хобта // Земля иркутская. - 2004. - № 3 (26). - С. 2-12.

15. Чернцов М. В. Отчет по работам по улучшению судоходных условий р. Ангары, 1894-1899 / М. В. Чернцов. - СПб., 1901. — 130 с.

\section{Информация об авторе}

Распопина Алена Александровна - кандидат исторических наук, доцент, кафедра истории и международных отношений, Байкальский государственный университет, 664003, г. Иркутск, ул. Ленина, 11; e-mail: alen_a77@mail.ru

\section{Author}

Alena A. Raspopina - PhD in History, Associate Professor, Department of History and International Relations, Baikal State University, 11 Lenin St., 664003, Irkutsk, Russia; e-mail: alen_a77@mail.ru 